\title{
Utility of Bolus of Insulin in Diabetic Ketoacidosis Management in Emergency Department
}

\author{
Sarra Jouini ${ }^{1,2}$, Fatma Hebaieb ${ }^{1,2}$, Rym Hamed ${ }^{1,2}$, Hana Hedhli ${ }^{1,2}$, Hela Manai ${ }^{1,2}$, Ines Chermiti ${ }^{1,2}$, Asma \\ Jendoubi ${ }^{1}$, Amel Maaref ${ }^{1}$, Amina Jebalii, ${ }^{1,2}$, Aymen Zoubli ${ }^{1,2}$ and Bechir Bouhajja ${ }^{1,2}$ \\ ${ }^{1}$ Department of Emergency, Charles Nicolle Hospital, Tunisia \\ ${ }^{2}$ EL Manar University, Tunisia
}

Submission: April 17, 2019; Published: April 30, 2019

*Corresponding author: Sarra Jouini, Emergency Department, Charles Nicolle Hospital, Tunis, Tunisia

Abstract

Aims: This study was designed to assess the efficacy and safety of initial bolus of regular insulin in the management of Diabetic Ketoacidosis (DKA) admitted in Emergency Department.

Methods: Placebo-controlled, double blind, prospective, randomized study including patients aged $>16$ years with moderate to severe DKA admitted in emergency department. Patients were randomly allocated to receive:

a) IV bolus of regular insulin $1 \mathrm{U} / 10 \mathrm{~kg}$;

b) IV bolus of normal saline. Standardization of:

i) the fluid therapy with normal saline and $5 \%$ dextrose

ii) the insulin therapy via continuous intravenous infusion;

iii) the potassium replacement. Outcomes data were time to acidosis resolution and occurrence of complications: hypoglycemia, hypokalemia.

Results: We enrolled 106 consecutive DKA patients. Mean age $=36 \pm 16.5$ years, sex ratio $=0.63$. Medical history, $\mathrm{N}(\%)$ : type 1 diabetes mellitus, 61 (57.5); type 2 diabetes mellitus, 31 (29.3); inaugural, 14 (13.2). There were no differences between the two groups in outcomes data: time to acidosis resolution (13.5 vs. 12.3 hours; $\mathrm{p}=0.37$ ), hypoglycemia ( $\mathrm{N}=10$ vs. $11 ; \mathrm{p}=0.66$ ), hypokalemia ( $\mathrm{N}=27$ vs. $31 ; \mathrm{p}=0.22$ ).

Conclusion: Administration of an initial bolus of insulin to patients with DKA was safe but not associated with significant benefit.

Keywords: Diabetic ketoacidosis; Insulin; Bolus; Emergency

Abbreviations: ADA: American Diabetes Association; DKA: Diabetic Ketoacidosis; ED: Emergency Department; IV: Intravenous

\section{Introduction}

Diabetic Ketoacidosis (DKA) is a life-threatening acute metabolic complication of diabetes mellitus [1-4]. It represents a common motif of consultation and admission in emergency department and its incidence is constantly increasing worldwide. Physiopathology of DKA is essentially based on combination of absolute or relative insulin deficiency with an increased level of counter regulatory hormones (glucagon, catecholamines, cortisol, and growth hormone) [2,4]. These metabolic disorders lead to metabolic acidosis, increased total body ketone concentration and electrolyte disturbances.

In last decades, management of DKA has been standardized based on correction of dehydration with crystalloids, insulin therapy and electrolyte replacement [2,3]. Consequently, DKA associated mortality was considerable decreasing [5-7]. Insulin therapy constitutes the cornerstone step in DKA management as it is the only efficient treatment for the neutralization of ketogenesis and counter-regulatory hormones effects, allowing the correction of organic metabolic acidosis. Currently, the treatment of DKA relies on the administration of regular insulin by continuous intravenous infusion [8]. However, the most appropriate insulin doses recommended in the DKA are not yet consensual and the utility of an initial dose of regular insulin remains controversial $[8,9]$. Pediatric guidelines for DKA treatment recommend against the bolus because of risks of hypoglycemia and cerebral edema caused by rapid changes in serum osmolarity $[10,11]$ although there is a lot of disagreement about adult guidelines. Therefore, this study was designed to assess the efficacy and safety of a priming dose or bolus of regular insulin in the management of diabetic ketoacidosis admitted in Emergency Department (ED). 


\section{Materials and Methods}

\section{Subjects}

Our study included patients aged more than 18 years old admitted to the ED of Charles Nicolle hospital in Tunisia for moderate to severe diabetic ketoacidosis defined by the American Diabetes Association (ADA) criteria associating : plasma glucose $>250 \mathrm{mg} / \mathrm{dL}, \mathrm{HCO}_{3^{-}}-<15 \mathrm{mEq} / \mathrm{L}$ and/or $\mathrm{pH} \leq 7.24$, and ketones in the urine. Patients with initial serum potassium levels $<3.3 \mathrm{mmol}$ / L or transferred from another health facility after initiation of DKA treatment were not eligible for this study. The exclusion criteria were: i) Organic renal failure with a creatinine clearance $<30 \mathrm{~mL} / \mathrm{min}$ prevents the imputation of metabolic acidosis in the only DKA; ii) Mixed forms, hyperosmolar hyperglycemic state (osmolarity $>320 \mathrm{mosm} / \mathrm{L}$ ) associated to diabetic ketoacidosis.

\section{Study design}

Placebo-controlled, double blinded, prospective, randomized, and single-center study over 20-month period (May 2013 December 2014). The purpose of this trial was to demonstrate the efficacy and safety of an initial bolus of regular insulin in the treatment of diabetic ketoacidosis admitted to the ED. Eligible patients were blindly randomized by a permuted-blocks randomization scheme into one of two group's medication: insulin bolus group and placebo bolus group. All physicians were blinded to received treatment; the randomization schema was distributed in a sealed envelope contained a paper that listed A (for insulin bolus) or B (for placebo bolus) to the nurses in charge of DKA management study protocol administration. Both two group's patients had medication by double routes: priming intravenous bolus followed by continuous intravenous infusion.

\section{Study deroulement}

Included patients were blindly randomized into one of the two treatment group's:

a) Bolus insulin group: initial intravenous dose of regular insulin (Actrapid $®$ laboratory Novo Nordisk A/S Denmark) at the dose of $0.1 \mathrm{UI} / \mathrm{Kg}$.

b) Bolus placebo group: initial intravenous dose of normal saline solution (taken from an insulin syringe equivalent to $0.1 \mathrm{UI} / \mathrm{Kg}$ weight).

All other modes of therapy (hydration fluid, insulin therapy and electrolyte replacement) were similar in the two groups. All patients received 1 liter of normal saline in the first hour; then they were blindly randomized into one of the two treatment groups and received bolus of insulin or placebo according to the envelope instruction. Thereafter, they all had

a) Insulin therapy by the administration of regular insulin via continuous intravenous infusion (0.1UI / Kg /hour) and in case of insulin resistance or decrease of glucose blood level less than $50 \mathrm{mg} / \mathrm{dL} /$ hour, the dose of regular insulin has been doubled; b) Hydrating solution using $0.9 \% \mathrm{NaCl}$ if glucose level > $250 \mathrm{mg} / \mathrm{dL}$ and $5 \%$ dextrose if glucose level $\leq 250 \mathrm{mg} / \mathrm{dL}$;

c) Potassium replacement according to the potassium level.

\section{Outcomes measurements}

The primary outcome was time to acidosis resolution defined as the time to achieve a glucose level less than $250 \mathrm{mg} / \mathrm{dL}, \mathrm{pH} \geq 7.3$ and bicarbonate of $\geq 18 \mathrm{mEq} / \mathrm{L}$; or the duration of intravenous (IV) insulin therapy.

The secondary outcomes were:

a) Time to reach capillary blood glucose $\leq 250 \mathrm{mg} / \mathrm{dL}$

b) Total dose of insulin IV

c) Occurrence of adverse events: Hypoglycemia defined by capillary blood glucose $<0.5 \mathrm{~g} / \mathrm{L}$, Hypokalemia defined by: $\mathrm{K}+<3.3 \mathrm{mmol} / \mathrm{L}$

d) Duration of hospital stay and recurrent DKA or capillary blood glucose $\geq 250 \mathrm{mg} / \mathrm{dL}$ during hospitalization.

\section{Statistical analysis}

SPSS 19.0 was used for different statistical analysis. Statistical significance was declared at $\mathrm{p}<0.05$.

\section{Ethics considerations}

The two therapeutic protocols studied in this work are recommended in international guidelines. In our current practice, the physician has the choice to apply one of both methods of DKA management in ED and our study was designed to compare the two protocols in order to standardize therapeutic attitudes in our department.

\section{Results}

\section{Clinical characteristics}

Over the study period, 134 patients with moderate to severe DKA presented to ED, and 106 patients were eligible. Figure 1 shows the patients flow diagram through this work. According to the randomization, fifty-five patients were in group A (bolus insulin) and fifty-one in group B (placebo bolus). There were no differences between the two groups in demographic and initial clinical data. Table $1 \& 2$ illustrate the baseline characteristics and initial clinico-biological data for all patients and both groups.

\section{Outcome measurement}

The length of hospital stays of patients admitted for moderate to severe DKA was about $40 \pm 29$ hours in our department. Eightynine patients (84\%) were discharged directly from ED. One case of death was reported resultant to septic shock. The major adverse effects experienced during DKA treatment in this study were mainly Hypokalemia [58 patients (54.7\%)] and hypoglycemia [21 patients (19.8\%)]. 


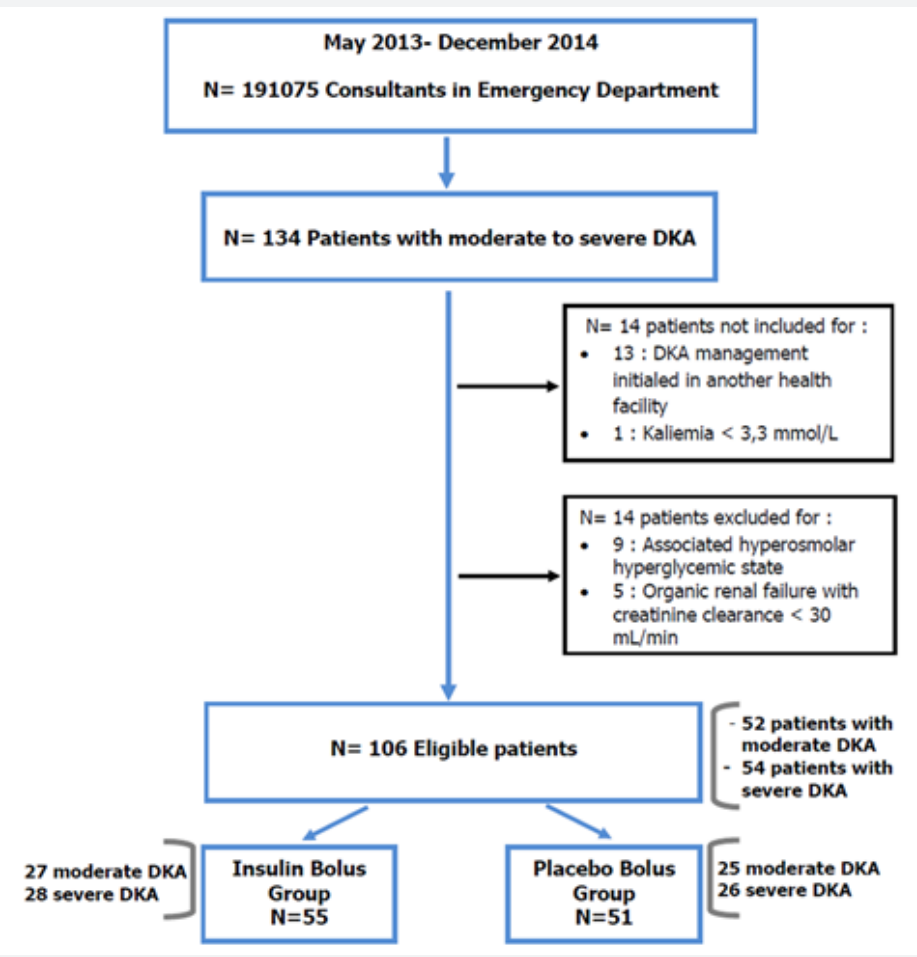

Figure 1: Patients flow through study.

Table 1: Demographic and clinical data on admission.

\begin{tabular}{|c|c|c|c|c|}
\hline & $\begin{array}{c}\text { Patients with Moderate to Severe } \\
\text { DKA }\end{array}$ & $\begin{array}{c}\text { Group A Bolus Insulin } \\
\qquad \mathrm{N}=55\end{array}$ & Group B Bolus Placebo N=51 & $\mathbf{p}$ \\
\hline Age (years) & $36+/-16.5$ & $33 \pm 16$ & $39 \pm 15$ & 0.54 \\
\hline Sex-ratio $(M / F)$ & 0.65 & $0.66(22 / 33)$ & $0.7(21 / 30)$ & 0.9 \\
\hline \multicolumn{5}{|l|}{ History of Diabetes: N (\%) } \\
\hline Type 1 diabetes & $61(57)$ & $34(62)$ & $27(53)$ & 0.35 \\
\hline Type 2 diabetes & $31(31,4)$ & $13(23)$ & $18(35)$ & 0.18 \\
\hline Inaugural DKA & $14(13.2)$ & $7(12.7)$ & 7 (13.7) & 0.88 \\
\hline \multicolumn{5}{|l|}{ Background Therapy: N (\%) } \\
\hline Insulin & $86(81.1)$ & $44(80)$ & $41(80.4)$ & 0.88 \\
\hline OAD & $12(11.3)$ & $5(9)$ & $7(13)$ & 0.47 \\
\hline \multicolumn{5}{|l|}{ Precipitating Factor: N (\%) } \\
\hline Treatment discontinuation & $52(49.1)$ & $27(49)$ & $25(49)$ & 0.99 \\
\hline Infection & $39(36.8)$ & $25(45.5)$ & $14(27)$ & 0.06 \\
\hline \multicolumn{5}{|l|}{ Initial Clinical Data: mean + SD } \\
\hline Glasgow Coma Scale (GCS) & $14.6 \pm 1.4$ & $14.6 \pm 1.1$ & $14.6 \pm 1.7$ & 0.81 \\
\hline Systolic Blood pressure (mmHg) & $119 \pm 19$ & $119 \pm 20$ & $120 \pm 18$ & 0.83 \\
\hline Respiratory rate (per min) & $26 \pm 6$ & $26 \pm 6$ & $25.5 \pm 6$ & 0.63 \\
\hline
\end{tabular}

$\mathrm{P}: p$-value for comparative study between groups A and B.

OAD: Oral anti diabetes; DKA: Diabetic ketoacidosis.

Table 2: Biological data on admission.

\begin{tabular}{|c|c|c|c|c|}
\hline & Patients with Moderate to Severe DKA & Group A Bolus Insulin N=55 & Group B Bolus Placebo N=51 & P \\
\hline Blood glucose level (g/L) & $5.22 \pm 0.9$ & $5.76 \pm 1.38$ & $6.23 \pm 1.41$ & 0.08 \\
\hline Anion gap (mEq/L) & $29.39 \pm 6.3$ & $28.9 \pm 6.2$ & $29.9 \pm 6.41$ & 0.38 \\
\hline pH & $7.13 \pm 0.15$ & $7.13 \pm 0.15$ & $7.13 \pm 0.15$ & 0.89 \\
\hline HCO3- (mmol/L) & $7.29 \pm 3.76$ & $7.3 \pm 3.5$ & $7.3 \pm 4$ & 0.99 \\
\hline
\end{tabular}




\begin{tabular}{|c|c|c|c|}
\hline $\begin{array}{c}\text { Serum potassium } \\
\text { (mmol/L) }\end{array}$ & $4.52 \pm 0.93$ & $4.54 \pm 0.94$ & $4.47 \pm 0.99$ \\
\hline Osmolarity (mosm/L) & $291.7 \pm 10.6$ & $292.7 \pm 10.3$ & $290.6 \pm 11.1$ \\
\hline
\end{tabular}

P: $p$-value for comparative study between groups $A$ and $B$.

The primary outcome based on the time to acidosis resolution (achieve a glucose level of $<250 \mathrm{mg} / \mathrm{dL}, \mathrm{pH} \geq 7.3$ and bicarbonate of $\geq 18 \mathrm{mEq} / \mathrm{L}$ ) was similar in both groups. Also, for secondary endpoints, there were no difference between the two groups: time to glucose control ( 6 vs 7 hours; $\mathrm{p}=0.18$ ), insulin dose to recovery (61 vs 62 Units; $p=0.82$ ), length of stay in ED (42.6 vs 36.7 hours; $\mathrm{p}=0.3$ ), complications: hypoglycemia ( $\mathrm{N}=10$ vs $11 ; \mathrm{p}=0.66$ ), hypokalemia ( $\mathrm{N}=27$ vs $31 ; \mathrm{p}=0.22$ ). Respecting recurrences of DKA and/or capillary blood glucose $\geq 250 \mathrm{mg} / \mathrm{dL}$ during hospitalization, they were similar too in groups A and B. Table 3 summarizes the outcome measurements data in both groups. Analysis of changes in blood glucose levels and anion gap during DKA treatment did not show any significant difference between the two groups (Figure 2).

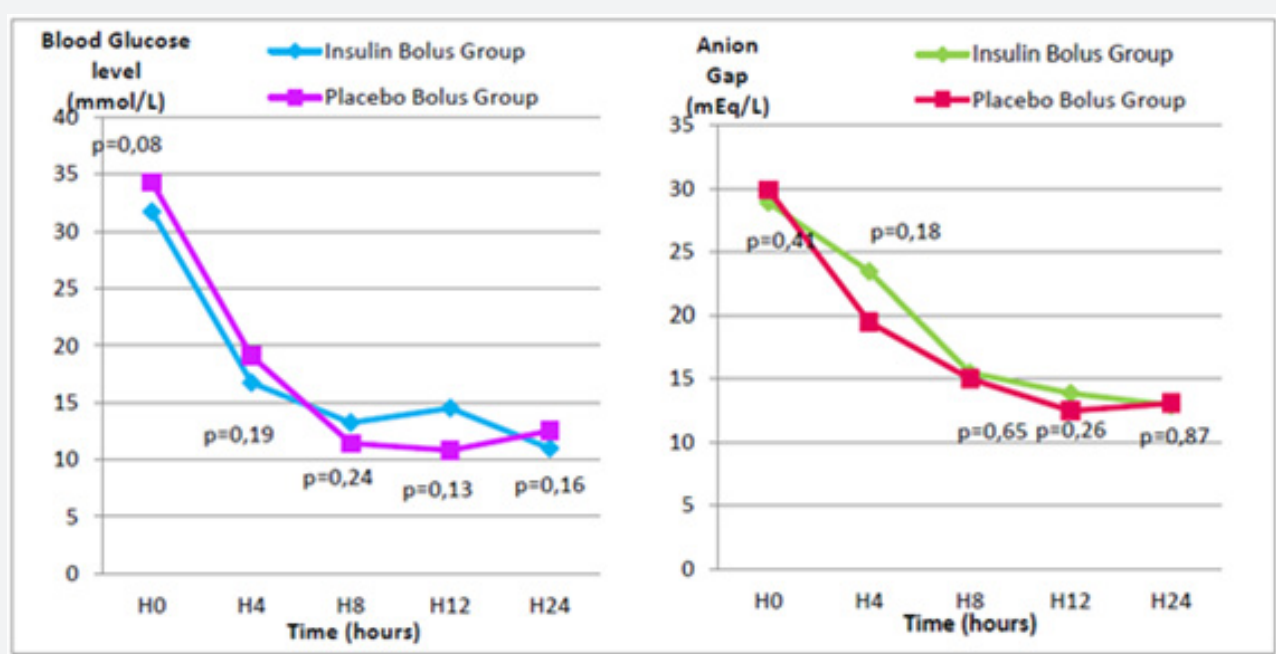

Figure 2: Changes in blood glucose levels and anion gap during diabetic ketoacidosis treatment.

Table 3: Outcome measurement data on both groups.

\begin{tabular}{|c|c|c|}
\hline & Group A Bolus Insulin & Group B Bolus Placebo \\
\hline Outcome Measurement: mean \pm SD & & $12.3 \pm 6.75$ \\
\hline Hours to acidosis resolution & $13.5 \pm 6.8$ & $7 \pm 0.18$ \\
\hline Hours to reach capillary blood glucose $\leq 250 \mathrm{mg} / \mathrm{dL}$ & $6 \pm 3.8$ & 0.37 \\
\hline Total dose of insulin IV (UI) & $61 \pm 37$ & $36.5 \pm 34$ \\
\hline Length of stay in ED stay (hours) & $42.6 \pm 31$ & 0.82 \\
\hline Adverse Events: N (\%) & & 0.3 \\
\hline Hypoglycemia & $10(18.2)$ & $31(21.56)$ \\
\hline Hypokalemia & $27(49)$ & 0.66 \\
\hline Evolution: N (\%) & & 0.22 \\
\hline Recurrent capillary blood glucose $\geq 250 \mathrm{mg} / \mathrm{dL}$ & $35(63.6)$ & $31(61)$ \\
\hline Recurrent DKA during hospitalization & $10(18)$ & $8(15.7)$ \\
\hline
\end{tabular}

\section{ED: Emergency Department.}

\section{Discussion}

In this double blinded, randomized, controlled trial involving 106 patients with moderate to severe DKA, the initial bolus of insulin failed to shorten the time of metabolic acidosis resolution, the time to achieve capillary blood glucose $\leq 2.5 \mathrm{~g} / \mathrm{L}$, as well the length of stay in ED. The evolution of clinic-biological and acidbase parameters was comparable in both groups. Similarly, the bolus of insulin was not associated with an increase in adverse events including the occurrence of episodes of hypoglycemia and hypokalemia.
Insulin therapy, the mainstay of DKA management, has been the subject of several studies to determine the best type of insulin, dose and modalities of administration (route, dilution, time of administration) [9,12-16]. Many studies have focused on the best route of administration of insulin therapy to conclude that although the intramuscular or subcutaneous route can be used in the treatment of non-complicated DKA (department of medicine, lower cost...), the intravenous route remains the most effective and safest way for the treatment of complicated DKA [12-15]. These data served as support for the international guidelines for 
DKA treatment, and currently insulin therapy is recommended by continuous intravenous infusion of regular insulin at low doses to begin one hour after rehydration according to initial serum potassium and to be adjusted to glycemic curve $[1,2,17,18]$. The ADA's recommendations published in 2009 proposed two regimens of insulin therapy in DKA management: a bolus of regular insulin at the dose of $0.1 \mathrm{U} / \mathrm{kg}$ followed by continuous infusion at the dose of $0.1 \mathrm{U} / \mathrm{kg} / \mathrm{h}$, or continuous infusion of regular insulin at the dose of $0.14 \mathrm{U} / \mathrm{kg} / \mathrm{h}$ within priming dose [9].

The need for the use of a priming or bolus dose of insulin in adult DKA main controversial. In fact, some authors proposed that with the usual doses of insulin, the serum insulin concentration is insufficient to correct metabolic disorders [19-21].Thus, by miming the physiological peak of insulin during hyperglycemia, a priming dose of insulin could help overcome the insulin resistance phase in DKA and shorten the total duration of insulin therapy and hospitalization $[20,21]$. However, the bolus of insulin can cause a rapid decrease in blood glucose levels without providing sufficient time to correct the acidosis, has been incriminated in the occurrence of serious complications such as hypoglycemia, hypokalemia and edema cerebral by some authors $[8,9,11,16,22]$. Some studies have investigated the utility of priming dose of insulin at different doses $(0.07 \mathrm{U} / \mathrm{kg}$ to $0.15 \mathrm{U} / \mathrm{kg})$ but none tested the recommended dose of insulin bolus $[9,16]$.

The primary outcome in our study, time to acidosis resolution, was about $13 \pm 7$ hours $(13 \pm 6.8$ in bolus insulin group vs $12.3 \pm 6.75$ in bolus placebo group; $\mathrm{p}=0.37$ ). It also referred to the duration of intravenous insulin therapy, which was comparable to literature results about 11 hours in the Kitabchi and Umpierrez studies $[9,14]$. Hypokalemia, serious complication of insulin therapy, has not been studied in many trials interested in the usefulness of insulin bolus in DKA treatment $[14,16]$. In the Kitabchi trial, no patient had hypokalemia during treatment however in our study, hypokalemia was seen in $54 \%$ of cases in both groups. The prominent contrast between our results and those of the Kitabchi study may be due to several factors including the fact that the Kitabchi study was conducted in a research center interesting a limited number of patients with a dedied health care staff for this trial [9]. However, our study was conducted in an emergency department with many consultations, a medical staff taking care of several patients at the same time and without relocated biology to measure serum potassium. This condition caused a delayed adaptation of potassium supplementation to kalemia explaining the occurrence of this complication in half of our cases. Whereas hypoglycemia was reported in $20 \%$ of our patients without difference in both groups similarly to literature findings $[2,14,21]$.

In this study, the length of stay in hospital was comparable in both groups shorter than reported in literature $[9,16]$. Patients with moderate to severe DKA are admitted to ED. They are discharged after acidosis resolution and addressed to endocrinologists to balance their diabetes mellitus. Thus, we can liberate places to admit other patients for various medical reasons.
Some weak points must be noted, mainly the nonmulticentric character of this trial and the absence of blood ketones measurement, more relevant parameter for evaluation of severity of DKA and its evolution within treatment. However, the originality of our work rests on several strength points as follows:

a) Evaluation of the usual recommended doses of insulin bolus and continuous infusion of regular insulin $(0.1 \mathrm{U} / \mathrm{kg}$ followed by $0.1 \mathrm{U} / \mathrm{kg} / \mathrm{h}$ ).

b) Exclusion of patients with associated hyperosmolar hyperglycemic state.

c) Double-blinded randomization.

d) Place of trial conducted in ED, current location of care and hospitalization of DKA patients in our country.

The treatment of diabetic ketoacidosis remains an interesting topic for medical research and should be always revised and adapted to local conditions.

\section{Conclusion}

In summary, our study concluded that the use of an initial bolus dose of insulin at $0.1 \mathrm{U} / \mathrm{kg}$ in moderate to severe diabetic keto-acidosis was safe but not associated with significant benefit compared to an adequate continued insulin infusion at $0.1 \mathrm{U} / \mathrm{kg} / \mathrm{h}$ dose.

\section{Acknowledgement}

All the medical and paramedical staff of the Emergency department, Charles Nicolle Hospital, Tunis, Tunisia

\section{References}

1. Nyenwe EA, Kitabchi AE (2011) Evidence-based management of hyperglycemic emergencies in diabetes mellitus. Diabetes Res Clin Pract 94(3): 340-351.

2. Kitabchi AE, Umpierrez GE, Miles JM, Fisher JN (2009) Hyperglycemic Crises in Adult Patients with Diabetes. Diabetes Care 32(7):1335-1343.

3. Fayfman M, Pasquel FJ, Umpierrez GE (2017) Management of Hyperglycemic Crises: Diabetic Ketoacidosis and Hyperglycemic Hyperosmolar State. Med clin North Am 101(3): 587-606.

4. Kitabchi AE, Umpierrez GE, Murphy MB, Kreisberg RA (2006) Hyperglycemic crises in adult patients with diabetes: a consensus statement from the American Diabetes Association. Diabetes Care 29(12): 2739-2748.

5. Kitabchi AE, Umpierrez GE, Fisher JN, Murphy MB, Stentz FB (2008) Thirty Years of Personal Experience in Hyperglycemic Crises: Diabetic Ketoacidosis and Hyperglycemic Hyperosmolar State. J Clin Endocrinol Metab 93(5): 1541-1552.

6. Thuzar M, Malabu UH, Tisdell B, Sangla KS (2014) Use of a standardized diabetic ketoacidosis management protocol improved clinical outcomes. Diabetes Res Clin Pract 104(1): e8-e11.

7. Henriksen OM, Prahl JB, Roder ME, Svendsen OL (2007) Treatment of diabetic ketoacidosis in adults in Denmark: a national survey. Diabetes Res Clin Pract 77(1): 113-119.

8. Savage MW, Dhatariya KK, Kilvert A, Rayman G, Rees JAE, et al. (2011) Joint British Diabetes Societies guideline for the management of diabetic ketoacidosis: Diabetic ketoacidosis guidelines. Diabet Med 28(5): 508-515. 
9. Kitabchi AE, Murphy MB, Spencer J, Matteri R, Karas J (2008) Is a Priming Dose of Insulin Necessary in a Low-Dose Insulin Protocol for the Treatment of Diabetic Ketoacidosis? Diabetes Care 31(11): 2081-2085.

10. Hoorn EJ, Carlotti APCP, Costa LAA, MacMahon B, Bohn G, et al. (2007) Preventing a drop in effective plasma osmolality to minimize the likelihood of cerebral edema during treatment of children with diabetic ketoacidosis. J Pediatr 150(5): 467-473.

11. Watts W, Edge JA (2014) How can cerebral edema during treatment of diabetic ketoacidosis be avoided? Pediatr Diabetes 15(4): 271-276.

12. Kitabchi AE, Ayyagari V, Guerra SM (1976) The efficacy of low-dose versus conventional therapy of insulin for treatment of diabetic ketoacidosis. Ann Intern Med 84(6): 633-638.

13. Fisher JN, Shahshahani MN, Kitabchi AE (1977) Diabetic ketoacidosis: low-dose insulin therapy by various routes. N Engl J Med 297(5) 238-241.

14. Umpierrez GE, Latif K, Stoever J, Cuervo R, Park L, et al. (2004) Efficacy of subcutaneous insulin lispro versus continuous intravenous regular insulin for the treatment of patients with diabetic ketoacidosis. Am J Med 117(5): 291-296.

15. Umpierrez GE, Cuervo R, Karabell A, Latif K, Freire AX, et al. (2004) Treatment of diabetic ketoacidosis with subcutaneous insulin aspart. Diabetes Care 27(8): 1873-1878.

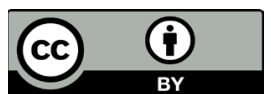

This work is licensed under Creative Commons Attribution 4.0 License

DOI: 10.19080/JAICM.2019.08.555749
16. Goyal N, Miller JB, Sankey SS, Mossallam U (2010) Utility of Initial Bolus Insulin in the Treatment of Diabetic Ketoacidosis. J Emerg Med 38(4): 422-427.

17. Middleton K, Hing E, Xu J (2007) National Hospital Ambulatory Medical Care Survey: 2005 outpatient department summary. Adv Data 389: 1-34.

18. Barski L, Kezerle L, Zeller L, Zektser M, Jotkowitz A (2013) New approaches to the use of insulin in patients with diabetic ketoacidosis. Eur J Intern Med 24(3): 213-216.

19. Butkiewicz EK, Leibson CL, O Brien PC, Palumbo PJ, Rizza RA (1995) Insulin therapy for diabetic ketoacidosis. Bolus insulin injection versus continuous insulin infusion. Diabetes Care 18(8): 1187-1190.

20. Barrett EJ, De Fronzo RA, Bevilacqua S, Ferrannini E (1982) Insulin resistance in diabetic ketoacidosis. Diabetes 31(10): 923-928.

21. Umpierrez GE, Kelly JP, Navarette JE, Casals MM, Kitabchi AE (1997) Hyperglycemic crisis in urban blacks. Archives of internal medicine 157(6): 669-675

22. Rewers A (2010) Current controversies in treatment and prevention of diabetic ketoacidosis. Adv Pediatr 57(1): 247-267.

Your next submission with Juniper Publishers will reach you the below assets

- Quality Editorial service

- Swift Peer Review

- Reprints availability

- E-prints Service

- Manuscript Podcast for convenient understanding

- Global attainment for your research

- Manuscript accessibility in different formats

( Pdf, E-pub, Full Text, Audio)

- Unceasing customer service

Track the below URL for one-step submission https://juniperpublishers.com/online-submission.php 